\title{
Development of Inhalable Nanostructured Lipid Carriers for Ciprofloxacin for Noncystic Fibrosis Bronchiectasis Treatment
}

This article was published in the following Dove Press journal: International Journal of Nanomedicine

\author{
Alanood S Almurshedi $\mathbb{1}^{1, *}$ \\ Hessah A Aljunaidel $^{2}$ \\ Bushra Alquadeib $\mathbb{D}^{\prime}$ \\ Basmah N Aldosari ${ }^{1}, *$ \\ Iman M Alfagih' \\ Salma S Almarshidy' \\ Eram KD Eltahir' \\ Amany Z Mohamoud' \\ 'Department of Pharmaceutics, College \\ of Pharmacy, King Saud University, \\ Riyadh, Saudi Arabia; ${ }^{2}$ Drug Regulatory \\ Affairs, Novartis, Riyadh, Saudi Arabia \\ *These authors contributed equally to \\ this work
}

Purpose: Ciprofloxacin (CIP) has poor lung targeting after oral inhalation. This study developed optimized inhalable nanostructured lipid carriers (NLCs) for CIP to enhance deposition and accumulation in deeper parts of the lungs for treatment of noncystic fibrosis bronchiectasis (NCFB).

Methods: NLC formulations based on stearic acid and oleic acid were successfully prepared by hot homogenization and in vitro-characterized. CIP-NLCs were formulated into nanocomposite micro particles (NCMPs) for administration in dry powder inhalation (DPI) formulations by spray-drying (SD) using different ratios of chitosan $(\mathrm{CH})$ as a carrier. DPI formulations were evaluated for drug content and in vitro deposition, and their mass median aerodynamic diameter (MMAD), fine particle fraction (FPF), fine particle dose (FPD), and emitted dose (ED) were determined.

Results: The CIP-NLCs were in the nanometric size range $(102.3 \pm 4.6 \mathrm{~nm})$, had a low polydispersity index $(0.267 \pm 0.12)$, and efficient CIP encapsulation $(98.75 \% \pm 0.048 \%)$, in addition to a spherical and smooth shape with superior antibacterial activity. The in vitro drug release profile of CIP from CIP-NLCs showed $80 \%$ release in $10 \mathrm{~h}$. SD of CIP-NLCs with different ratios of $\mathrm{CH}$ generated NCMPs with good yield $(>65 \%)$. The NCMPs had a corrugated surface, but with increasing lipid: $\mathrm{CH}$ ratios, more spherical, smooth, and homogenous NCMPs were obtained. In addition, there was a significant change in the FPF with increasing lipid:CH ratios $(P<0.05)$. NCMP-1 (lipid: $\mathrm{CH}=1: 0.5$ ) had the highest FPD $(45.0 \mu \mathrm{g})$ and FPF (49.2\%), while NCMP-3 (lipid:CH = 1:1.5) had the lowest FPF (37.4\%). All NCMP powders had an MMAD in the optimum size range of $3.9-5.1 \mu \mathrm{m}$.

Conclusion: Novel inhalable CIP NCMP powders are a potential new approach to improved target ability and delivery of CIP for NCFB treatment.

Keywords: ciprofloxacin, NCFB, NLCs, NCMPs, DPI, aerosolization

\section{Introduction}

Noncystic fibrosis bronchiectasis (NCFB) is a chronic respiratory disease that seriously affects the patients' quality of life. ${ }^{1}$ NCFB is characterized by permanent and abnormal bronchial dilation and is associated with increased morbidity and mortality due to airway obstruction, poor gas transfer, and chronic bronchial infection. ${ }^{2}$ Chronic bronchial infection damages the host's defenses and the lung epithelium and can also cause a vicious cycle of infection and inflammation with persistent symptoms and disease progression. ${ }^{3}$ NCFB has a heterogeneous
Correspondence: Alanood S Almurshedi Department of Pharmaceutics, College of Pharmacy, King Saud University, P.O. Box 58488, Riyadh, I I594, Saudi Arabia

Tel +966 II 8055013

Fax +966 II 4697507

Email marshady@ksu.edu.sa
International Journal of Nanomedicine 2021:16 2405-24I7 
respiratory pathology with many etiologies. Post infectious disease is commonly reported, although up to $53 \%$ of cases are idiopathic. ${ }^{1,2}$

Recent treatment guidelines recommend many approaches to NCFB management, such as airway clearance, airway drug treatment (primarily with bronchodilators), and long-term antibiotic use. ${ }^{4}$ However, one of the main therapeutic challenges is clinical management of chronic airway infection due to recurrent antibiotic resistance (especially to oral antibiotics) and the common side effects of systemically administered antibiotics. ${ }^{5}$ These challenges make NCFB a difficult disease to treat, and there is currently no approved longterm antibacterial therapy for NCFB. ${ }^{6}$ Therefore, there is a need for developing new therapies to effectively treat the underlying chronic infection, decreasing bronchial suppuration and exacerbations and preventing disease progression. Recently, drug delivery to the lungs via dry powder inhalers (DPI) represents a possible delivery route for the treatment of different respiratory diseases. ${ }^{7}$ This non-injective route has many merits over other sites of administration because it has a large surface area, which contain sufficient capillary vessels for rapid absorption. The absorbed drug can directly reach the systemic circulation, bypassing the first-pass metabolism in the liver. ${ }^{8}$ Therefore, compared to the oral or parenteral drug delivery route, direct delivery of low concentrations of antibiotics to the lungs causes a higher accumulation of antibiotics at the infection site, while decreasing systemic exposure and the risk of toxicity and producing therapeutic effects with smaller drug doses. ${ }^{9}$

Dry powder inhalers (DPIs) are an attractive choice for pulmonary drug delivery as they have good physiochemical stability, no need for reconstitution of powders, easy incorporation of high concentration of drug, acceptable pulmonary deposition through the patient's respiration, and higher opportunity of particle/carrier engineering. ${ }^{10}$ In addition to easy to operate, portable and cost effective. $^{11}$ DPI can be made more flexible for use with a wide range of active pharmaceutical components and diseases. $^{12}$ Inhaled antibiotics for the management of NCFB is now recommended as a possible option for patients with severe infections or recurrent aggravations secondary to long-lasting bacterial colonization. ${ }^{13}$ The rationale for inhaled antibiotic treatment depends on improved therapeutic drug delivery at the site of infection which needed to improve antibiotic efficacy, with possibly lower systemic exposure that should lessen the risk of toxicity. $^{14}$

Nanoparticle formulations are used in many therapeutic fields, especially inhalation drug delivery systems, which ensure drug release after pulmonary administration. ${ }^{15}$ Nano formulations have been increasingly proposed for lung drug delivery applications of antibacterial, ${ }^{16}$ antifungal, ${ }^{17}$ and antiviral drugs, ${ }^{18}$ which can be made to achieve appropriate morphological and aerodynamic characteristics, in the form of dry powders for pulmonary inhalation. $^{19}$

Solid lipid nanoparticles (SLNs) are lipophilic nanoscale aqueous suspension and have the ability to incorporate drugs as a nanosystem, SLNs have evolved as a drug delivery system that can be potentially used for pulmonary drug targeting. In addition, they are physiologically compatible and physio chemically stable carrier systems, protect the incorporated active compounds against degradation, and have a relatively low production cost. ${ }^{20}$ Nanostructured lipid carriers (NLCs) are the second generation of SLNs. NLCs are composed of a solid lipid and liquid lipid blend, which leads to an imperfect matrix structure and less dense lipid packaging and generates space to incorporate drugs in the matrix. Therefore, NLCs have a higher drug encapsulation efficiency (EE) and stability during long-term storage compared to SLNs. ${ }^{21}$ In addition, because of inexpensive required materials, lipid biocompatibility, ease of manufacture, controlled drug release, and stability, NLCs can overcome the disadvantages of other colloidal carriers. Mostly, NLCs predominate polymeric nanoparticles (NPs) with regard to safety and biocompatibility and are considered the least toxic NPs when administrated in vivo. ${ }^{22}$

Among specific inhalable antibiotics, ciprofloxacin (CIP; ciprofloxacin hydrochloride) is a broad-spectrum second-generation fluoroquinolone antibiotic used in oral and parenteral formulations. CIP has proven bactericidal efficacy against gram-positive and gram-negative bacteria. $^{23}$ It is currently indicated for the treatment of systemic infections, including respiratory infections. CIP's bactericidal activity is concentration dependent: the higher the peak concentration, the greater the bactericidal activity. Therefore, CIP is an especially suitable candidate for inhaled drug products where high drug concentrations can be achieved in the lungs. ${ }^{24}$ However, CIP has poor lung targeting after oral inhalation. The absorption of CIP from the lungs into the systemic circulation is rapid, with a half-life of less than $1 \mathrm{~h}$ in rat lungs, and is suboptimal 
for lung delivery. ${ }^{25}$ One approach to extending the residence time of CIP in the lungs, compared to unencapsulated formulations, is to encapsulate CIP in lipid nanoparticle CIP formulations. ${ }^{9}$

This study developed and evaluated stable DPI formulations loaded with CIP-NLCs using one-step spray-drying (SD) for high pulmonary deposition, increasing drug accumulation in deeper parts of the lungs.

\section{Materials and Methods \\ Materials}

CIP was kindly given as a gift sample by Spimaco Aldawaeia (Al-Qassim, Saudi Arabia). Stearic acid, oleic acid, Tween ${ }^{\circledR} 80$, chitosan $(\mathrm{CH})$, deacetylated lowmolecular-weight chitin, and a dialysis bag (molecular weight cut-off $10 \mathrm{kDa}$ ) were purchased from SigmaAldrich (St. Louis, MO, USA). In addition, six bacterial species including four gram-negative (Escherichia coli American Type Culture Collection, ATCC 25,922 Klebsiella ATCC 13,883, salmonella ATCC 25,566, shigella ATCC 11,060 and Pseudomonas aeruginosa ATCC 9027) and two gram-positive strains (Bacillus cereus ATCC 5119 and Staphylococcus aureus ATCC 25,923) were obtained from the ATCC (Manassas, VA, USA). Mueller Hinton agar Scharlau was purchased from Scharlab, S.L. (Barcelona, Spain), and a $5 \mu \mathrm{g}$ CIP disk, CT0425B, was purchased from Oxoid Limited (UK). All other chemicals used were of analytical grade.

\section{NLC Preparation}

CIP-NLCs were prepared by hot homogenization, as previously described with slight modifications. ${ }^{26}$ Briefly, the lipid phase comprised CIP $(0.1 \% \mathrm{w} / \mathrm{v})$ dissolved in a mixture of stearic acid and oleic acid and heated at $75^{\circ} \mathrm{C}$, while a hot aqueous phase was prepared by dispersing Tween ${ }^{\circledR} 80(1 \% \mathrm{w} / \mathrm{v})$ in double-distilled water at $75^{\circ} \mathrm{C}$ and then adding it to the lipid phase with highspeed stirring (Ultra Turrax T25, IKA, Germany) for $6 \mathrm{~min}$ at $8000 \mathrm{rpm}$. Next, the pre-emulsion obtained was subjected to hot homogenization using a Yellow line DI25 basic high-shear homogenizer (IKA) at 12,000 rpm and $75^{\circ} \mathrm{C}$. The formulations obtained were subjected to bath sonication (Bransonic, 5510E-DTH, Mexico) for $5 \mathrm{~min}$ at $60 \mathrm{~W}$ for uniform size distribution. Blank (nonloaded) NLCs were prepared using the same procedure. Finally, the formulations were solidified by storing them for $24 \mathrm{~h}$ at $4^{\circ} \mathrm{C}$ before further analysis.

\section{CIP Quantification by HPLC}

CIP was quantified using high-performance liquid chromatography (HPLC), as previously described with some modifications and validation. ${ }^{27}$ Briefly, we coupled a Waters Breeze2TM HPLC system (Waters Corporation, Milford, MA, USA) with an automated sampling system (WatersTM 2695 Plus Autosampler; Waters Corporation) at $4^{\circ} \mathrm{C}$ and a photodiode array detector (WatersTM 2998; Waters Corporation). We also used a C18 column with a guard cartridge $(\mathrm{C} 18)$ at $25^{\circ} \mathrm{C}$. The software used was Breeze2 (WaterTM). The mobile phase was a mixture of $25 \mathrm{mM}$ phosphate buffer $(\mathrm{pH} 2.4)$ and acetonitrile (70\%:30\% v/v) at a flow rate of $1 \mathrm{~mL} / \mathrm{min}$ and a UV detection wavelength of $290 \mathrm{~nm}$. The method was linear over a concentration range of $0.5-25 \mu \mathrm{g} / \mathrm{mL}$, and the modified method was precise and accurate with a limit of detection and a limit of quantitation of 0.3 and $1.1 \mu \mathrm{g} / \mathrm{mL}$, respectively.

\section{CIP-NLC Characterization}

Measurement of Particle Size, Polydispersity Index, and Zeta Potential

The intensity mean particle size (PS), polydispersity index (PDI), and zeta potential (ZP) of CIP-NLCs were determined using dynamic light scattering (DLS; Zetasizer Nano ZS; Malvern Instruments, UK). CIP-NLC dispersions were suitably diluted with double-distilled water at room temperature (RT). All measurements were performed in triplicate.

\section{Morphology}

We observed the shape of CIP-NLC dispersions using transmission electron microscopy (TEM; JEM 1400; JEOL Ltd., Peabody, MA, USA). Briefly, CIP-NLCs dispersions were diluted with double-distilled water and fixed on a carbon-coated copper grid, which was allowed to dry. Next, the dispersions were scanned and photographed.

\section{Determination of Encapsulation Efficiency and Loading Capacity}

The encapsulation efficiency (EE) and Loading Capacity (LC) of CIP in the NLCs were indirectly determined by measuring the concentration of free CIP in the aqueous phase, according to Pignatello et $\mathrm{al}^{28}$ and analyzed by above mentioned HPLC method (CIP Quantification by HPLC). The EE was estimated using Eq. 1:

$$
\mathrm{EE} \%=\left(\left(\mathrm{W}_{\text {total }}-\mathrm{W}_{\text {free }}\right) / \mathrm{W}_{\text {total }}\right) * 100
$$

While the loading capacity ( $\mathrm{LC} \%$ ) capacity is calculated using Eq. 2: 


$$
\mathrm{LC} \%=\left(\left(\mathrm{W}_{\text {total }}-\mathrm{W}_{\text {free }}\right) / \mathrm{W}_{\text {lipid }}\right) * 100
$$

where $\mathrm{W}_{\text {total }}$ is the total weight of the drug added, $\mathrm{W}_{\text {free }}$ is the weight of un-encapsulated free drug and $\mathrm{W}_{\text {lipid }}$ is total weight of lipid in the formulation. All samples were analyzed in triplicate.

\section{In vitro Drug Release Analysis}

In vitro drug release experiments were performed using the Franz diffusion cell. Briefly, CIP-NLCs were evaluated using a dialysis membrane that had been previously soaked for $24 \mathrm{~h}$ in a release medium. Phosphate-buffered saline (PBS; pH 7.4) was used as the receptor medium. The samples were placed in the donor compartment of the Franz diffusion cell. During the experiments, the buffer solution in the receptor side was maintained at $37^{\circ} \mathrm{C} \pm$ $0.5^{\circ} \mathrm{C}$. At predetermined time intervals and with continuous stirring, samples were withdrawn from the receiver compartment and replaced by the same volume of fresh PBS to maintain the sink condition.

Next, we analyzed the samples using HPLC. At the end of the experiment, we determined the kinetic parameters for in vitro data in order to determine the best-fit kinetic model (zero, first, or Higuchi order) to estimate the CIP release mechanism from CIP-NLCs; the best correlation coefficient $(r)$ value represented the best release mechanism.

\section{Antimicrobial Activity}

We performed an antimicrobial sensitivity test of CIPNLCs using the disk diffusion method. ${ }^{29}$ Both gramnegative and gram-positive strains were used. First, we isolated the colony of organisms on selective media for $24 \mathrm{~h}$. Next, we cultured the colony in nutrient broth for $24 \mathrm{~h}$ and then adjusted the optical density to McFarland turbidity. Subsequently, we prepared Mueller-Hinton agar for testing the sensitivity and then applied the new formulation CIP-NLCs in disks. We used a $5 \mu \mathrm{g}$ CIP disk as the positive (+ve) control and blank (empty) NLCs as the negative (-ve) control. Finally, after $24 \mathrm{~h}$ incubation, we measured the growth inhibition zones around the disks. The spray dried powders were tested using the same method against E. coli and Pseudomonas aeruginosa.

\section{Spray Drying of CIP-NLCs}

We used SD to prepare NCMPs with different ratios of $\mathrm{CH}$. Briefly, we dispersed a CIP-NLC sample in CH solution at different lipid:CH ratios (1:0.5, 1:1, and 1:1.5 w/w), mixed them for $5 \mathrm{~min}$ at $25^{\circ} \mathrm{C}$, and spray-dried the mixture using a Büchi B-290 mini spray dryer (Büchi Labortechnik, Flawil, Switzerland) with a $0.7 \mathrm{~mm}$ nozzle orifice. The feed rate was $10 \%$, aspirator capacity $100 \%$, atomizing air flow $400 \mathrm{~L} / \mathrm{h}$, inlet temperature $90^{\circ} \mathrm{C}$, and outlet temperature $\sim 30-35^{\circ} \mathrm{C}$. We detached dry NCMPs powders from the air stream via a cyclone (Büchi Labortechnik) and stored them in a desiccator at RT until further analysis.

\section{Spray-Dried CIP-NLC Characterization Dry Powder Yield}

The NCMP powder yield was calculated as the percentage mass of the predictable total powder yield as follows: ${ }^{30}$

$$
\operatorname{Yield}(\%)=\left(\mathrm{W}_{\text {sd }} / \mathrm{W}_{\mathrm{t}}\right) * 100
$$

Where $\mathrm{W}_{\text {sd }}$ is the weight of dry powder after spray drying and $\mathrm{W}_{\mathrm{t}}$ is the weight of total dry mass used for the preparation.

\section{Dry Powder Drug Content}

We dispersed $\sim 10 \mathrm{mg}$ of spray-dried NCMP powders into a suitable volume of PBS ( $\mathrm{pH}$ 7.4), followed by sonication for $5 \mathrm{~min}$. Next, we added ethanol and then filtered the sample through a $0.22 \mu \mathrm{m}$ membrane filter. Finally, we used HPLC to determine the CIP content.

\section{Dry Powder Morphology and Size}

The morphology of NCMP powders was examined using scanning electron microscopy (SEM; JSM-6060LV; JEOL Ltd., Japan). Briefly, we fixed a layer of NCMP powders on carbon adhesive tape on a stub. Next, the layer was sputter-covered with platinum under an argon atmosphere at $180 \mathrm{~mA}$ for $1 \mathrm{~min}$ using a JEC-3000FC auto fine coater (JEOL Ltd., Japan). Finally, the NCMP powders were randomly photographed by scanning of the stub.

\section{Antimicrobial Activity}

The spray dried powders were tested using the same method as in 2.4.5 section, against E. coli and Pseudomonas aeruginosa.

\section{In vitro Aerosolization}

We evaluated the aerosolization of the spray-dried NCMP powders using the Next Generation Impactor ${ }^{\mathrm{TM}}$ (NGI) connected to a Copley HCP5 pump (Copley Scientific, UK). In accordance with the aerosol specifications given in the United States Pharmacopoeia (USP) Chapter $601,{ }^{31}$ we loaded the NCMP powders into a hydroxypropyl methylcellulose capsule (size 3). Each capsule contained $12.5 \mathrm{mg}$ of NCMP powder, which equaled $5 \mathrm{mg}$ of CIP. Next, the samples were placed in a Cyclohaler ${ }^{\circledR}$ (Teva Pharmaceutical Industries, Israel) and run for $4 \mathrm{~s}$ at a flow rate of $60 \mathrm{~L} / \mathrm{min}$. Each plate 
Table I Effect of Different Tween ${ }^{\circledR} 80$ Concentrations on Particle Size, Polydispersity Index and Zeta Potential of Blank NLC (Mean \pm SD, $n=3$ )

\begin{tabular}{|l|c|c|c|c|}
\hline Composition (\%w/v) & NLC-0.25 & NLC-0.5 & NLC-I & NLC-I.25 \\
\hline Stearic acid & 3 & 3 & 3 & 3 \\
Oleic acid & $\mathrm{I}$ & $\mathrm{I}$ & $\mathrm{I}$ & $\mathrm{I}$ \\
Tween ${ }^{\circledR} 80$ & 0.5 & $\mathrm{I}$ & $\mathrm{I}$ & 2 \\
Water & Up to $50 \mathrm{~mL}$ & Up to $50 \mathrm{~mL}$ & Up to $50 \mathrm{~mL}$ & Up to $50 \mathrm{~mL}$ \\
PS $(\mathrm{nm})$ & $342.5 \pm 7.1$ & $2240.6 \pm 8.2$ & $102.3 \pm 4.6$ & $106 \pm 3.5$ \\
PDI & $0.521 \pm 0.72$ & $0.41 \pm 0.43$ & $0.267 \pm 0.12$ & $0.289 \pm 0.11$ \\
ZP $(\mathrm{mV})$ & $-28.5 \pm 1.5$ & $-29.6 \pm 0.7$ & $-31.4 \pm 1.3$ & $-27.1 \pm 1.7$ \\
\hline
\end{tabular}

of the NGI was coated with a methanolic solution of $1 \%$ Tween $^{\circledR} 80$, and the powder deposited in each plate was collected by rinsing with a known volume of distilled water.

The CIP content was quantified using HPLC, as mentioned before. The emitted fraction, the fine particle dose (FPD), the fine particle fraction (FPF) and mass median aerodynamic diameter (MMAD) were determined. FPD refers to the dose reaching the target site which is determined as the sum of powder deposited in NGI stages and MOC with aerodynamic diameters less than $5 \mu \mathrm{m}$. FPF express as a fraction of the emitted dose with an MMAD of $<5 \mu \mathrm{m}$, deposited deep in the lungs. MMAD is the mass median aerodynamic diameter and determined using online software (MMAD calculator.com). ${ }^{32}$ All experiments were carried out in triplicate $(n=3)$.

\section{Statistical Analysis}

We used one-way analysis of variance (ANOVA) (SPSS Statistics; IBM Corporation, Armonk, NY, USA) to analyze data. $P<0.05$ was considered a statistically significant difference between the set of formulations.

\section{Results and Discussion}

\section{Rationale Behind Components and Formulations}

In this study, we selected NLC components on the basis of their purpose: controlling CIP release. As previously mentioned, NLCs act as a controlled drug release system, but their components largely affect their behavior. We produced blank and CIP-loaded NLCs using hot homogenization. Stearic acid, a long-chain fatty acid, was selected as the solid lipid because it is biocompatible, safe, and suitable for drug delivery. ${ }^{33}$ In addition, the release rate and EE depend on the stearic acid concentration. ${ }^{34}$ Oleic acid was selected as the liquid lipid based on CIP solubility and slow dissolution. In addition, higher oleic acid content decreases the viscosity inside NLCs and, therefore, the surface tension, forming smaller NLC particles with a smoother surface. ${ }^{35}$ CIP also has amine and carboxylic acid functional groups, which interact with oleic acid by forming ionic chemical interactions and hydrogen bonds, respectively. Therefore, higher drug loading is expected by the use of oleic acid. ${ }^{36}$

In this study, we also analyzed the effects of the Tween ${ }^{\circledR}$ 80 concentration $(0.25-1.25 \% \mathrm{w} / \mathrm{v})$, keeping the lipid concentration constant $(1.5 \% \mathrm{w} / \mathrm{v})$, at $12,000 \mathrm{rpm}$ homogenization speed (Table 1). Increasing the Tween ${ }^{\circledR} 80$ concentration from $0.25 \%$ to $1 \% \mathrm{w} / \mathrm{v}$ in blank NLCs significantly decreased the PS from $368.5 \pm 9.7$ to $102.3 \pm 4.6 \mathrm{~nm}$, but there was no significant decrease with an additional increase in the Tween ${ }^{\circledR} 80$ concentration. These results showed that increasing the surfactant concentration significantly affects the particle size, which could be due to a significant decrease in surface tension and surface-free energy during homogenization because of high-shear conditions. ${ }^{37}$

The PS and PDI decreased from $342.5 \pm 7.1$ to $102.3 \pm$ $4.6 \mathrm{~nm}$ and from $0.521 \pm 0.15$ to $0.267 \pm 0.12$, respectively, with increasing homogenization speed $(10,000$ to $12,000 \mathrm{rpm})$. The increase in the PS because of an increase in the kinetic energy of particles leads to agglomeration. ${ }^{38}$ However, there was no significant change in the ZP. In addition, increasing the homogenization speed to more than $12,000 \mathrm{rpm}$ resulted in blackening of the formulation and precipitation. In addition, it was difficult to control the process because of froth and air bubble formation. Therefore, we selected 12,000 rpm as the optimal homogenization speed for NLC preparation.

In a dry powder formulation, a carrier excipient plays an important role owing to the small amount of drug in the final formulation and in delivering the drug into its target of pulmonary macrophages. Drug particles should exhibit an aerodynamic diameter (MMAD) smaller than $5 \mu \mathrm{m}$. MMAD about $1-5 \mu \mathrm{m}$ is required for targeting deposition to the small airways. Therefore, for effective pulmonary deposition, the powders must include particles $1-5 \mu \mathrm{m}$ in diameter. 
Also, most DPI formulations use carriers to improve in vitro and in vivo aerosolization performances. The carriers should be non-toxic, facilitate drug preparation and administration, protect the drug from degradation, and help steady drug release. ${ }^{39}$ The carrier presents bulk to the DPIs, which ease the handling, dispensing, and actuation of the targeted therapeutic agent, which is very crucial for low dose DPIs. ${ }^{40}$

In this study, a chitosan, deacetylated low-molecularweight chitin, was chosen as a carrier. Chitosan is a biodegradable natural polymer with an excellent potential for pharmaceutical applications owing to its non-toxicity, biocompatibility, mucoadhesive properties and high charge density. ${ }^{41}$ At present different evidence support the usage of chitosan as a carrier to deliver active ingredients deep inside the lungs from a dry powder inhaler. ${ }^{42,43}$ Therefore, CIP dry powder prepared using chitosan as a carrier was expected to show improved drug release in lower airways and the alveolar regions of the lung.

\section{CIP-NLC Characterization}

\section{Size and ZP}

We characterized the obtained CIP-NLCs with regard to their PS and PDI. The PS of NLCs was $102.3 \pm 4.6 \mathrm{~nm}$, which confirmed the nanometric range of all formulations tested. The PDI was less than $0.267 \pm 0.12$, indicating homogeneity of particle distribution, typical of monodispersed systems. ${ }^{36}$ The ZP determines the surface charge of NLCs, which significantly affects their stability through electrostatic repulsion, which, in turn, inhibits their aggregation. All formulations tested showed a significant negative charge. The ZP was $18.3 \pm 0.153$ for CIP-NLCs and $-22.7 \pm 0.45$ for blank NLCs.

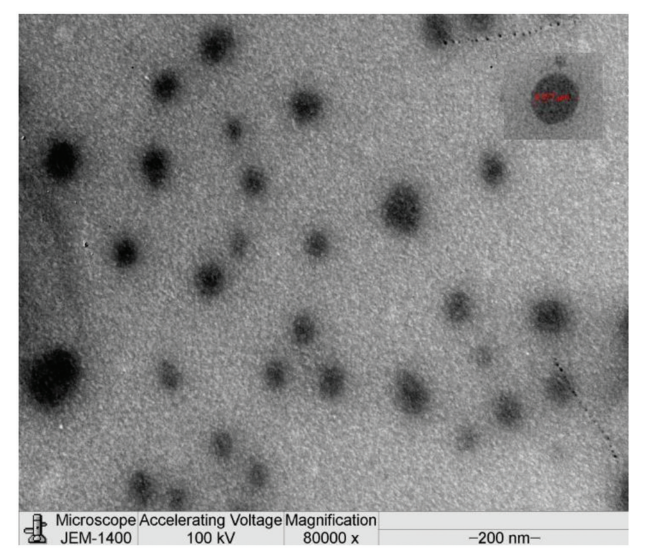

\section{Morphology}

Figure 1 shows the TEM image of CIP-NLCs. The CIP-NLCs were uniformly spherical in shape with a smooth surface, and their size was homogenous. They were less than $100 \mathrm{~nm}$ in size, which was in agreement with DLS measurements.

\section{Entrapment Efficiency}

The entrapment efficiency and loading capacity of CIPNLCs were $98.75 \% \pm 0.048 \%$ and $13.34 \pm 1.92 \%$, respectively. The type of lipid used for the preparation of lipid NPs has a significant impact on the encapsulation efficiency and drug loading capacity of the formulations. Gamal A. Shazly found that Cip solid lipid NPs containing stearic acid showed the highest EE values of $73.94 \%$ with emulsification-sonication method. ${ }^{44}$ Also, Dharmendra Jain et al obtained an EE of $38.71 \% \pm 2.38 \%$ to $8.66 \% \pm 1.64 \%$ for SLN formulations by using microemulsion technique. ${ }^{45}$ Moreover, the liquid lipid content of oleic acid can trap high amounts of a drug and can decrease drug crystallization. The use of liquid oil in NLC formulations limits the lipid matrix recrystallization and forms amorphous or imperfect crystalline structures, which provide more space to incorporate drugs (an increase in the EE) and also decrease drug explosion or leakage during storage. In addition, the presence of a surfactant (Tween ${ }^{\circledR} 80$ ) in NLC formulations could improve the drug loading capacity of CIP. High drug content also means a high accepted drug content, which indicates high stability and ensures a residual concentration of the nano-loaded drug that shows acceptable activity. ${ }^{46}$

\section{In vitro Drug Release}

In vitro CIP release from the CIP-NLCs in PBS buffer $(\mathrm{pH}$ 7.4) was analyzed using the Franz diffusion cell. Figure 2 shows the release profiles of CIP from CIP-NLCs and free

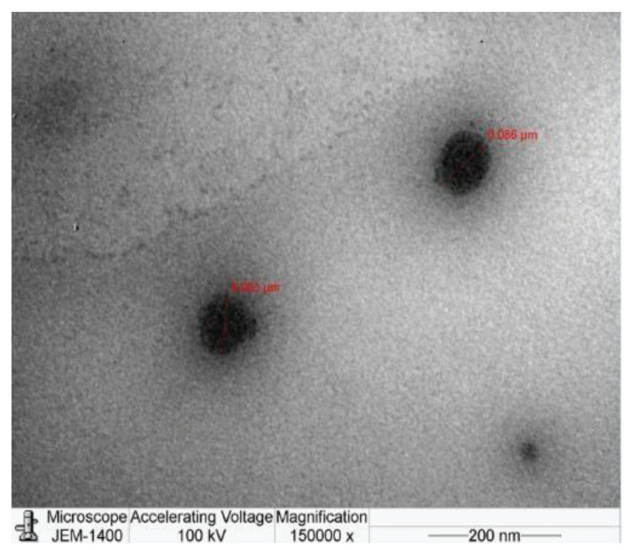

Figure I Transmission electron microscopy images of nanoparticles loaded with ciprofloxacin (CLP-NLC) at 8000 and I50,000× magnification power. 


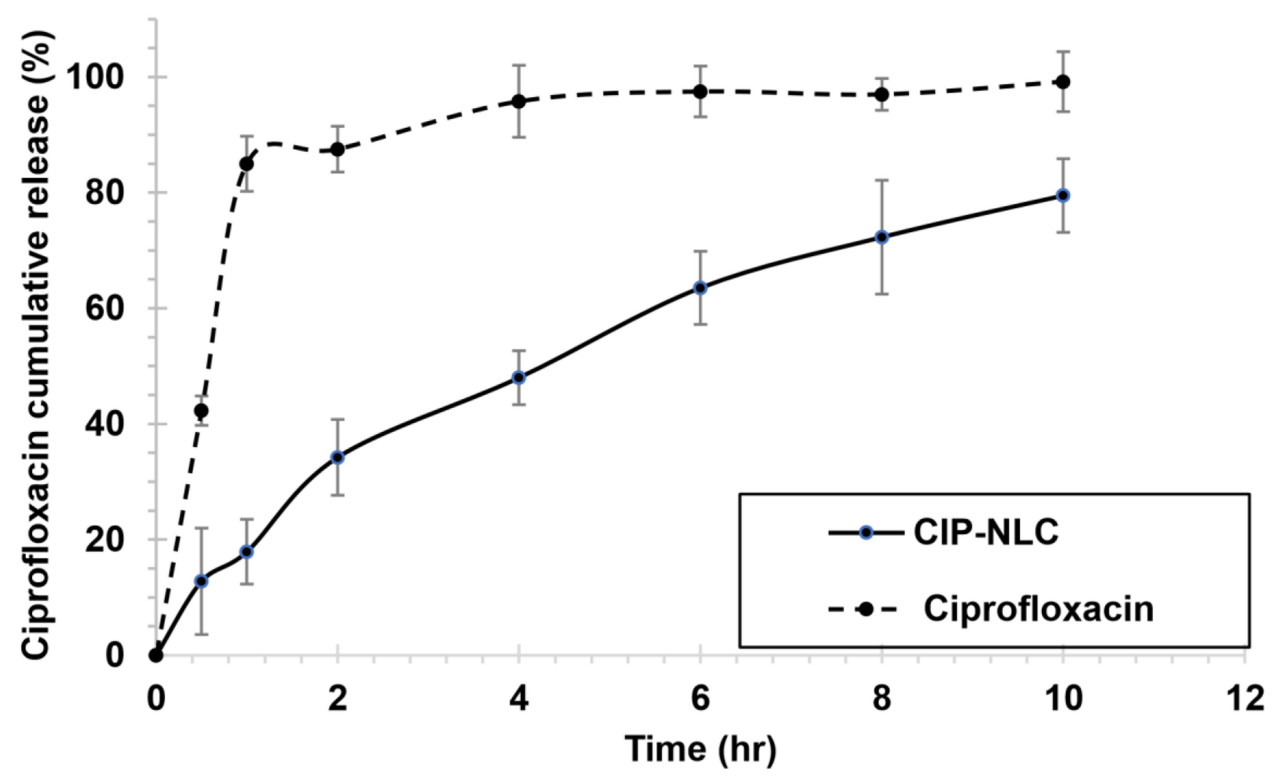

Figure 2 In vitro release of free ciprofloxacin and nanostructured lipid carriers loaded with ciprofloxacin (CIP-NLC) in phosphate buffer saline (PBS) PH 7.4 at $37^{\circ} \mathrm{C}$.

CIP over time. As shown, 95.8\% $\pm 6.23 \%$ of free CIP was released within $4 \mathrm{~h}$, while only $\sim 48 \% \pm 4.67 \%$ of CIP was released from CIP-NLCs after the same period, indicating prolonged drug release. Initially, CIP was rapidly released from CIP-NLCs $(34.22 \% \pm 6.56 \%$ in the first $2 \mathrm{~h})$ and then gradually slowed. The initial rapid release might be due to the presence of some amount of drug on the surface of the NLCs. In addition, the drug release corresponds to the core of the solid lipid in the NLCs.

The CIP-NLCs released $37.34 \% \pm 2.08 \%$ of CIP over 2 $\mathrm{h}$, and the release was sustained for $10 \mathrm{~h}$, probably because the dispersed drug can only be released slowly from lipid matrices through dissolution and diffusion (Figure 2). ${ }^{47}$ Table 2 shows the release data kinetics for the CIP-NLCs prepared. We found a better fit to the Higuchi diffusion model. The data were analyzed for confirmation of the relative validity of the diffusion model using the equation given by Korsmeyer et al. ${ }^{38}$ The calculated $n$ value was more than 0.43 and less than 1, indicating anomalous (non-Fickian) transport probably because the diffusion refers to a combination of both diffusion- and erosion-controlled drug releases. ${ }^{48}$

Table 2 Release Kinetic Data of the Investigated Nanoparticles Loaded with Ciprofloxacin (CIP-NLC)

\begin{tabular}{|c|c|c|c|c|c|}
\hline \multirow{2}{*}{$\begin{array}{l}\text { Formula } \\
\text { Code }\end{array}$} & \multirow{2}{*}{$\begin{array}{l}\text { Zero- } \\
\text { Order } \\
\text { Model } r\end{array}$} & \multirow{2}{*}{$\begin{array}{l}\text { First- } \\
\text { Order } \\
\text { Model }\end{array}$} & \multirow{2}{*}{$\begin{array}{l}\text { Higuchi } \\
\text { Diffusion } \\
\text { Model } r\end{array}$} & \multicolumn{2}{|c|}{ Peppas Model } \\
\hline & & & & $\boldsymbol{r}$ & $\mathbf{N}$ \\
\hline CIP-NLC & 0.9718 & 0.7556 & 0.9958 & 0.8153 & 0.6153 \\
\hline
\end{tabular}

\section{Antimicrobial Activity of CIP-NLCs}

We performed an antimicrobial sensitivity test on MuellerHinton agar using the Kirby-Bauer disk diffusion method according to standard operational procedures. ${ }^{49}$ The antimicrobial agent tested was $5 \mu \mathrm{g}$ of CIP (+ve control), and CIPNLCs which showed growth inhibition zones (Figure 3). While there is no inhibition zone with the blank NLCs which were free of CIP (-ve control). As expected, the CIPNLCs resulted in larger zones of inhibition and more prolonged inhibitory effects than +ve control (Figure 3A). The CIP-NLCs increasingly inhibited bacterial growth for both gram-negative and gram-positive strains. Also, a comparison of the diameters of growth inhibition zones showed that CIP-NLC induced growth inhibition was lower in Staphylococcus aureus and Bacillus sp. compared to other samples (Figure 3A). This was probably because CIP is more strongly effective on gram-negative than on grampositive bacteria. ${ }^{50}$ Moreover, we observed growth inhibition in the first 30 of the experiment for CIP-NLCs, which increased with an increase in the amount of CIP diffused from formulations. The delay in antimicrobial effect was likely due to early limitations in dissolution of CIP and its diffusion from the formulations. These results showed that CIP inhibits bacterial growth for a longer period compared to free CIP and blank NLCs and that CIP-NLCs have superior antibacterial activity compared to free CIP. The explanations for these results could be owing to the lipophilic nature of NLCs that enhance the cellular entering of CIP into the bacterial membrane and the nano size of the particles. 
Enhancing the effectiveness of CIP loaded into nanoparticles is reported in many studies. ${ }^{51,52}$ These findings are attributed to several issues, including: helped penetration of antibiotic into the bacterial cells, improved drug delivery to its site of action, and the higher stability of the encapsulated drug into the NPs. These proposed mechanisms of enhancement were confirmed by the lack of any antimicrobial activity of blank formulations, which was in agreement with the conclusions of other studies. ${ }^{53,54}$

\section{Characterization of Spray-Dried CIP-NLCs \\ Drug Content and Yield}

Since CIP-NLCs have an average size of $102.3 \pm 4.6 \mathrm{~nm}$, they cannot be delivered directly via inhalation because most of the inhaled drug will be exhaled and little will be deposited deep in the lungs. ${ }^{55}$ Therefore, in this study, we formulated CIP-NLCs into NCMPs to be administrated as DPI formulations. The drug content of NCMPs was relatively high (92-95.2\%), and the spray-dried NCMP powder yield was $64.5-78.3 \%$ (Table 3 ). The lowest yield $(64.50 \% \pm$ $3.58 \%$ ) was obtained for NCMP-3 (at lipid: $\mathrm{CH}=1: 1.5 \mathrm{w} /$ $\mathrm{w})$, and the maximum yield $(78.3 \% \pm 3.5 \%)$ was obtained for NCMP-1 (at lipid:CH $=1: 0.5 \mathrm{w} / \mathrm{w}$ ). The $\mathrm{CH}$ ratio affected the production yield, with an increasing ratio of $\mathrm{CH}$ resulting in a decreased yield (Table 3), which can be attributed to some of the liquid droplets attaching to the inside wall of the drying chamber and cyclone of the spray dryer. The concentration of carriers was found to play a crucial role for the yield and drying efficiency. ${ }^{56}$ Though

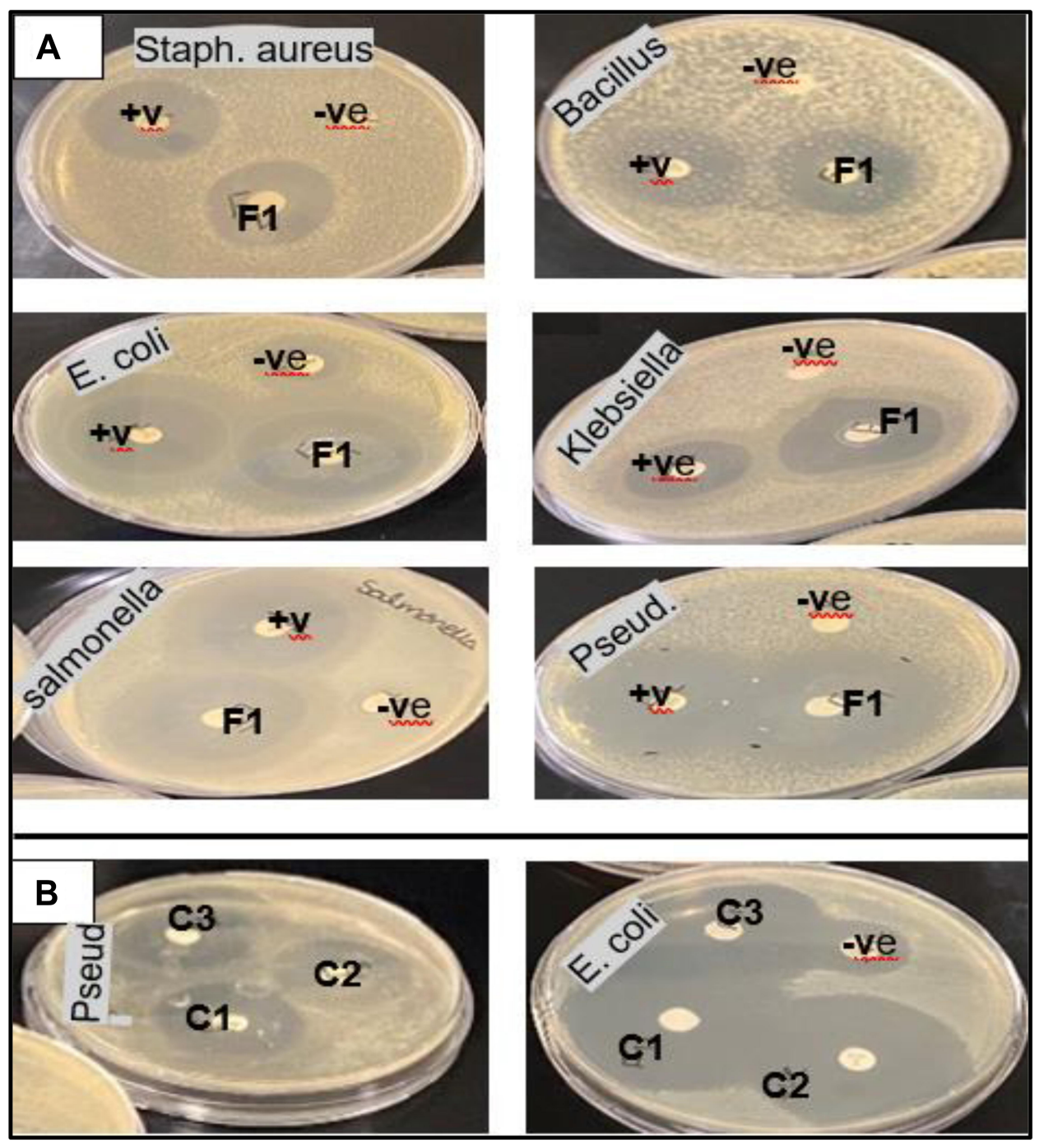

Figure 3 Zone of inhibition of ciprofloxacin on different microbial strains. +ve: control (5 $\mu$ g of CIP), -ve: blank or non-loaded NLCs. (A) Ciprofloxacin loaded nanostructured lipid carrier (CIP-NLC), (B) spray dried CIP-NLC with different chitosan: lipid ratios (CI: NCMPI, C2: NCMP2, C3 NCMP3). 
Table 3 The \% Yield, Drug Content, Fine Particle Dose (FPD), Percentage Fine Particle Fraction (FPF), and Mass Median Aerodynamic Diameter (MMAD) of NCMPs (Mean \pm S.D., $n=3$ )

\begin{tabular}{|c|c|c|c|c|c|c|}
\hline Formula & Ratio (Lipid:CH) & Yield (\%) & Drug Content (\%) & FPD $(\mu g)$ & FPF (\%) & MMAD $(\mu \mathrm{m})$ \\
\hline NCMP-I & I: 0.5 & $78.77 \pm 3.16$ & $95.2 \pm 5.9$ & $45.0 \pm 4.2$ & $49.2 \pm 5.8$ & $3.90 \pm 0.1$ \\
\hline NCMP-2 & I: I & $72.16 \pm 2.33$ & $91.4 \pm 4.7$ & $38.7 \pm 5.2$ & $42.7 \pm 7.5$ & $4.83 \pm 0.8$ \\
\hline NCMP-3 & I: 1.5 & $64.50 \pm 3.58$ & $92.8 \pm 6.2$ & $36.4 \pm 4.6$ & $37.5 \pm 4.6$ & $5.10 \pm 0.7$ \\
\hline
\end{tabular}

the product yield could be improved by increasing the spray capacity, making the samples at high concentration became tricky as a consequence of some problems as sticking occurred so that particle collection became hard and as a result, product yield might decrease contrary to be predicted. ${ }^{57}$ This was described previously by Learoyd et al, with powders spray dried using 30\% v/v aqueous ethanol formulations of terbutaline sulfate as a model drug, chitosan as a drug release modifier and leucine as an aerosolization enhancer. ${ }^{58}$ The yield decreases with a gradual increase in the lipid: $\mathrm{CH}$ ratio because of powder adherence to the chamber wall due to some of the liquid droplets attaching to the inside wall of the drying compartment and the spray dryer cyclone. ${ }^{48}$ Also, the yield of the biodegradable $\mathrm{CH}$ microspheres containing vancomycin hydrochloride, prepared by SD with different ratios of $\mathrm{CH}$ is quite low because of powder adherence to the chamber wall and decreased cyclone productivity for fine powder collection. ${ }^{59}$

\section{Morphology}

SEM images of NCMPs (Figure 4) show that the NCMPs were spherical with a corrugated surface. An increase in the lipid: $\mathrm{CH}$ ratio produces smoother and more spherical NCMPs because of the fast internal evaporation of droplets. Because of the faster water evaporation from the droplets throughout the SD process, and later after the water completely evaporates, the surface layer collapses, leading to a wrinkled structure. ${ }^{60}$ Increasing the lipid: $\mathrm{CH}$ ratio increases the viscosity of the fed solution, leading to slower evaporation. $\mathrm{CH}$ microspheres produced by $\mathrm{SD}$ using a low-viscosity $\mathrm{CH}$ solution have a ridged surface (a little wrinkled), but those produced using a highviscosity $\mathrm{CH}$ solution have a smooth surface. ${ }^{61}$ The wrinkled or Corrugated surface of the spray-dried powder has many advantages, such as decreased aggregation by decreasing the cohesiveness and increasing the dispersibility, resulting in enhanced lung deposition. ${ }^{62}$

\section{Antimicrobial Activity of Spray Dried Powder}

In our study, we investigated the antimicrobial activities of the CIP-NLCs after spray drying using different ratios of low-molecular-weight chitosan (NCMP1, NCMP 2, and NCMP3). Figure 3B shows the plates with zones of inhibition, of Pseudomonas aeruginosa and E. Coli, around the medicated discs after 24 hours of incubation at $37^{\circ} \mathrm{C}$. Interestingly, the results revealed that there is no statistically significant difference $(\mathrm{p}>$ 0.05 ) between the antimicrobial activity of CIP-NLCs and the spray dried powders. This is in contrast to the earlier reports which stated that the antibacterial activity of CIP-loaded chitosan NPs were more pronounced on Gram -ve and Gram +ve bacteria, the concept of increased efficacy of drugs functionalized with nontoxic carriers. ${ }^{63,64}$ An additional explanation for our observations will need to be further investigated. Moreover, the antibacterial activity of chitosan NPs is influenced by various intrinsic and extrinsic factors, related to molecular weight, degree of deacetylation concentration, $\mathrm{pH}$, and test organism. ${ }^{65}$ Bharathala et al who reported that use of medium molecular weight chitosan with $85 \%$ degree of deacetylation, at physiological $\mathrm{pH}$ exhibited limited antibacterial efficacy in all strains of gram -ve and gram + ve bacteria. ${ }^{66}$

\section{Aerosolization}

The NGI is used for the determination of the aerodynamic particle size distribution of the dose released from dry powder inhalers using compendial methods. It can classify particles based upon their size which is beneficial in predicting in vivo deposition of particles. Therefore, the therapeutic efficacy of DPIs is determined by their aerodynamic properties. The MMAD is one of the important issues that control deposition of particles in the different stages of the NGI and consequently in the lung airways. ${ }^{67}$ The amount of CIP from each formulation in each stage of NGI device was analyzed by HPLC system. In vitro lung modeling with the NGI results in FPD, FPF, and MMAD of the NCMP powders (Table 3 ) that have been defined in the Methods section. The MMAD should be not $>5 \mu \mathrm{m}$ to pass into the smaller bronchial airways if peripheral deposition is essential. ${ }^{68}$ All the NCMP powders had 


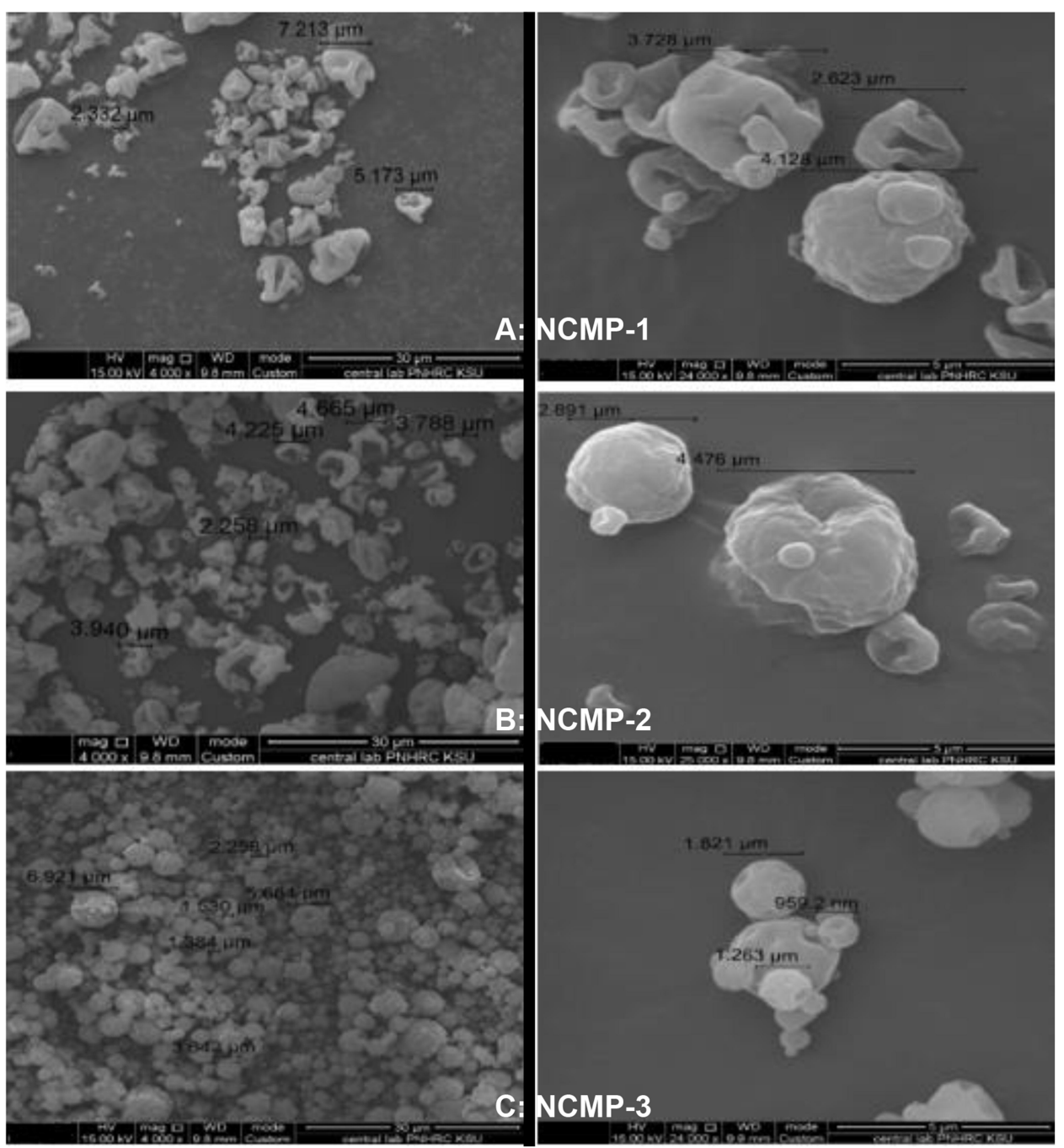

Figure 4 SEM photographs of liposomes spray dried in the presence of different ratios of chitosan (w/w). (A) NCMPI at lipid:CH ratio of I:0.5, (B) NCMP2 at lipid:CH ratio I:I, (C) NCMP3 at lipid:CH ratio of I:I.5. Pictures were taken at $4000 \times$ and $25,000 \times$ magnifications.

high MMAD values which are in the optimal size range of 3.9-5.1 $\mu \mathrm{m}$. The FPD and FPF of the NCMP powders indicated the amount and fraction of CIP particles reaching the lower part of the airways. Comparing all formulations, NCMP-1 (at lipid: $\mathrm{CH}$ ratio of 1:0.5) had the highest $\%$ FPF and FPD values, $49.2 \%$ and $45.0 \mu \mathrm{g}$ of CIP, respectively. On the other side, NCMP-3 (at lipid: $\mathrm{CH}$ ratio of $1: 1.5$ ) has the lowest FPF $\%$ and FPD, 37.5\% and $36.4 \mu \mathrm{g}$ of CIP, respectively, because of its more corrugated surface. Increasing the lipid: $\mathrm{CH}$ ratio in the formulations caused a significant change in the FPF $(P<$ 0.05 ). In addition, about $50 \%$ (FPF) was deposited mostly in respirable airways ( $1-5 \mathrm{um})$, delivering a $45 \mu \mathrm{g}$ dose (FPD), that is, $45 \mu \mathrm{g}$ of the drug delivered by the drug delivery system, which contained $100 \mu \mathrm{g}$ of the drug, was deposited at the target site. Higher FPF and MMAD values could be the result of the aggregation of particles, friction, or interlocking between the particles, which might not disaggregate upon aspiration. The FPF identified the efficiency of drug deposition in the lower airways. NCMP-1 had the highest FPF and FPD, indicating that it is effective in delivering the maximum amount of CIP to the lower respiratory tract. The reason is the correlation between the FPD and the FPF. Therefore, when the FPF increases, the expected amount of CIP delivered to the target site also increases. All NCMP powders prepared had a suitable MMAD in the optimum size range of 3.9-5.1 $\mu \mathrm{m}$, indicating the suitability of the NCMP powders for targeting the deeper parts of the lungs as stated by different groups of researchers. ${ }^{69,70}$ The MMAD showed effective delivery of NCMPs with CIP to the deeper parts of the lungs. 


\section{Conclusions}

This study developed optimized, inhalable NLCs for CIP for NCFB treatment. The optimized CIP-NLCs showed good physical stability, as indicated by the ZP, high entrapment efficiency and controlled drug release properties. The inhalable CIP NCMP powders are a potential new approach to improved target ability and delivery of CIP for NCFB treatment, indicating deep lung deposition. Overall, CIP-NLCs in DPI formulations have the potential to be a strong therapeutic choice for NCFB patients with chronic pathogenic infection.

\section{Acknowledgments}

The authors thank the Deanship of Scientific Research and RSSU at King Saud University for their technical support. This research project was supported by a grant from "Researchers Supporting Project number (RSP-2020/ 223), King Saud University, Riyadh, Saudi Arabia.

\section{Disclosure}

Hessah A Aljunaidel is an employee of Novartis. The authors report no other conflicts of interest for this work.

\section{References}

1. McShane PJ, Naureckas ET, Tino G, Strek ME. Non-cystic fibrosis bronchiectasis. Am J Respir Crit. 2013;188(6):647-656. doi:10.1164/ rccm.201303-0411CI

2. Loebinger MR, Wells AU, Hansell DM, et al. Mortality in bronchiectasis: a long-term study assessing the factors influencing survival. Eur Respir J. 2009;34:843-849. doi:10.1183/09031936.00003709

3. Smith MP. CME: non-cystic fibrosis bronchiectasis. $J R$ Coll Physicians Edinb. 2011;41(2):132-139. doi:10.4997/JRCPE.2011. 217

4. Pasteur MC, Bilton D, Hill AT. British Thoracic Society guideline for non-CF bronchiectasis. Thorax. 2010;65(Suppl 1):1-58. doi:10.1136/ thx.2010.136119

5. Regan KH, Hill AT. Risk of development of resistance in patients with non-cystic fibrosis bronchiectasis treated with inhaled antibiotics. Curr Pulmonol Rep. 2018;7:63-71. doi:10.1007/s13665018-0202-7

6. King PT. The pathophysiology of bronchiectasis. Int $J$ Chron Obstruct Pulmon Dis. 2009;4:411-419. doi:10.2147/COPD.S6133

7. Maselli DJ, Keyt H, Restrepo MI. Inhaled antibiotic therapy in chronic respiratory diseases. Int $J$ Mol Sci. 2017;18(5):1062. doi:10.3390/ijms 18051062

8. Pilcer G, Amighi K. Formulation strategy and use of excipients in pulmonary drug delivery. Int J Pharm. 2010;392:1-19. doi:10.1016/j. ijpharm.2010.03.017

9. Cipolla D, Gonda I, Chan H-K. Liposomal formulations for inhalation. Ther Deliv. 2013;4(8):1047-1072. doi:10.4155/tde.13.71

10. Mehta P. Dry powder inhalers: a focus on advancements in novel drug delivery systems. J Drug Deliv. 2016;2016:1-17. doi:10.1155/ 2016/8290963

11. Zhou QT, Leung SSY, Tang P, Parumasivam T, Loh ZH, Chan HK. Inhaled formulations and pulmonary drug delivery systems for respiratory infections. Adv Drug Deliv Rev. 2015;85:83-99.
12. Garbuzenko OB, Saad M, Pozharov VP, Reuhl KR, Mainelis G, Minko T. Inhibition of lung tumor growth by complex pulmonary delivery of drugs with oligonucleotides as suppressors of cellular resistance. Proc Natl Acad Sci U S A. 2010;107:10737-10742. doi:10.1073/pnas.1004604107

13. Chang A, Bell S, Byrnes C, et al. Chronic suppurative lung disease and bronchiectasis in children and adults in Australia and New Zealand. A position statement from the Thoracic Society of Australia and New Zealand and the Australian Lung Foundation. Med J Aust. 2010;193(6):356-365. doi:10.5694/j.1326-5377.2010. tb03949.x

14. Xu MJ, Dai B. Inhaled antibiotics therapy for stable non-cystic fibrosis bronchiectasis: a meta-analysis. Ther Adv Respir Dis. 2020;14:1753466620936866. doi:10.1177/1753466620936866

15. Alexescu TG, Tarmure S, Negrean V, et al. Nanoparticles in the treatment of chronic lung diseases. J Mind Med Sci. 2019;6 (2):224-231. doi:10.22543/7674.62.P224231

16. Woods A, Rahman KM. Antimicrobial molecules in the lung: formulation challenges and future directions for innovation. Future Med Chem. 2018;10:575-604. doi:10.4155/fmc-2017-0162

17. Merlos R, Amighi K, Wauthoz N. Recent developments in inhaled triazoles against invasive pulmonary Aspergillosis. Curr Fungal Infect Rep. 2014;8(4):331-342. doi:10.1007/s12281-014-0199-5

18. Pindiprolu SKS, Kumar CSP, Golla VSK, Likitha P, Chandra S, Ramachandra RK. Pulmonary delivery of nanostructured lipid carriers for effective repurposing of salinomycin as an antiviral agent. Med Hypotheses. 2020;143:109858. doi:10.1016/j.mehy.2020.109858

19. Khosa A, Reddi S, Saha RN. Nanostructured lipid carriers for site-specific drug delivery. Biomed Pharmacother. 2018;103: 598-613. doi:10.1016/j.biopha.2018.04.055

20. Puri A, Loomis K, Smith B, et al. Lipid-based nanoparticles as pharmaceutical drug carriers: from concepts to clinic. Crit Rev Ther Drug Carrier Syst. 2009;6:523-580. doi:10.1615/CritRevTherDrugCarrierSyst.v26. i6.10

21. Muller RH, Radtke M, Wissing SA. Solid lipid nanoparticles (SLN) and nanostructured lipid carriers (NLC) in cosmetic and dermatological preparations. Adv Drug Deliv Rev. 2002;54:S131-S155. doi:10.1016/S0169-409X(02)00118-7

22. Muller RH, Keck CM. Challenges and solutions for the delivery of biotech drugs - a review of drug nanocrystal technology and lipid nanoparticles. J Biotechnol. 2004;113(1-3):151-170. doi:10.1016/j. jbiotec.2004.06.007

23. Andersson MI. Development of the quinolones. $J$ Antimic Chemother. 2003;51(90001):1-11. doi:10.1093/jac/dkg212

24. Liu C, Lin L, Huang Z, et al. Novel inhalable ciprofloxacin dry powders for bronchiectasis therapy: mannitol-silk fibroin binary microparticles with high-payload and improved aerosolized properties. AAPS PharmSciTech. 2019;20(2):85. doi:10.1208/s12249-0191291-5

25. Cipolla D, Blanchard J, Gonda I. Development of liposomal ciprofloxacin to treat lung infections. Pharmaceutics. 2016;8(1):6-15. doi:10.3390/pharmaceutics 8010006

26. Nnamani P, Ugwu A, Ibezim E, et al. Preparation, characterization and in vitro antibacterial property of ciprofloxacin-loaded nanostructured lipid carrier for treatment of Bacillus subtilis infection. $J$ Microencapsul. 2019;36:32-42. doi:10.1080/02652048.2019.15 82724

27. Imre S, Dogaru MT, Vari CE, Muntean T, Kelemen L. Validation of an HPLC method for the determination of ciprofloxacin in human plasma. J Pharm Biomed Anal. 2003;33:125-130. doi:10.1016/ S0731-7085(03)00151-1

28. Pignatello R, Leonardi A, Fuochi V, Petronio Petronio G, Greco AS, Furneri PM. A method for efficient loading of ciprofloxacin hydrochloride in cationic solid lipid nanoparticles: formulation and microbiological evaluation. Nanomaterials. 2018;8(5):304-312. doi:10.33 90/nano8050304 
29. National Committee for Clinical Laboratory Standards. Performance Standards for Antimicrobial Disk Susceptibility Test: Approved Standard M2-A 6. NCCLS. Wayne, PA; 1997.

30. Mehanna MM, Mohyeldin SM, Elgindy NA. Rifampicincarbohydrate spray-dried nanocomposite: a futuristic multiparticulate platform for pulmonary delivery. Int J Nanomed. 2019;14:9089. doi:10.2147/IJN.S211182

31. Aerosols, nasal sprays, metered-dose inhalers, and dry powder inhalers monograph. USP 29-NF 24: United States Pharmacopoeia and the National Formulary: The Official Compendia of Standards. Vol. 29/24. Rockville, MD: United States Pharmacopeial Convention; 2006:2617-2636.

32. Benke E, Farkas Á, Balásházy I, Szabó-Révész P, Ambrus R. Stability test of novel combined formulated dry powder inhalation system containing antibiotic: physical characterization and in vitro-in silico lung deposition results. Drug Dev Ind Pharm. 2019;45 (8):1369-1378. doi:10.1080/03639045.2019.1620268

33. Kelidari HR, Moazeni M, Babaei R, et al. Improved yeast delivery of fluconazole with a nanostructured lipid carrier system. Biomed Pharmacother. 2017;89:83-88. doi:10.1016/j.biopha.20 17.02.008

34. Alarifi S, Massadeh S, Al-Agamy M, Aamery MA, Al Bekairy A, Yassin AE. Enhancement of ciprofloxacin activity by incorporating it in solid lipid nanoparticles. Trop J Pharm Res. 2020;19:909-918. doi:10.4314/tjpr.v19i5.1

35. Youssef A, Dudhipala N, Majumdar S. Ciprofloxacin loaded nanostructured lipid carriers incorporated into in-situ gels to improve management of bacterial endophthalmitis. Pharmaceutics. 2020;12 (6):572. doi:10.3390/pharmaceutics12060572

36. Torge A, Wagner S, Chaves PS, et al. Ciprofloxacin-loaded lipid-core nanocapsules as mucus penetrating drug delivery system intended for the treatment of bacterial infections in cystic fibrosis. Int $J$ Pharm. 2017;527(1-2):92-102. doi:10.1016/j.ijpharm.2017.05.013

37. Khames A, Khaleel MA, El-Badawy MF, El-Nezhawy AOH. Natamycin solid lipid nanoparticles-sustained ocular delivery system of higher corneal penetration against deep fungal keratitis: preparation and optimization. Int $J$ Nanomed. 2019;14:2515-2531. doi:10. 2147/IJN.S190502

38. Korsmeyer RW, Doelker GR, Buri P, Peppas NA. Mechanisms of solute release from porous hydrophilic polymers. Int $J$ Pharm. 1983;15:25-35. doi:10.1016/0378-5173(83)90064-9

39. Patel B, Gupta N, Ahsan F. Particle engineering to enhance or lessen particle uptake by alveolar macrophages and to influence the therapeutic outcome. Eur J Pharm Biopharm. 2015;89:163-174. doi:10. 1016/j.ejpb.2014.12.001

40. Ibrahim M, Verma R, Garcia-Contreras L. Inhalation drug delivery devices: technology update. Med Devices (Auckl). 2015;8:131. doi:10.2147/MDER.S48888

41. Ahmad MI, Ungphaiboon S, Srichana T. The development of dimple-shaped chitosan carrier for ethambutol dihydrochloride dry powder inhaler. Drug Dev Ind Pharm. 2015;41(5):791-800. doi:10. 3109/03639045.2014.903493

42. Huang Y, Huang Z, Zhang X, et al. Chitosan-based binary dry powder inhaler carrier with nanometer roughness for improving in vitro and in vivo aerosolization performance. Drug Deliv Transl Res. 2018;8(5):1274-1288. doi:10.1007/s13346-01 8-0564-y

43. Guan X, Zhang W. Applications of chitosan in pulmonary drug delivery. Role Novel Drug Delivery Veh Nano Biomed. 2019;28:163.

44. Shazly GA. Ciprofloxacin controlled-solid lipid nanoparticles: characterization, in vitro release, and antibacterial activity assessment. Biomed Res Int. 2017;2017.

45. Jain D, Banerjee R. Comparison of ciprofloxacin hydrochloride-loaded protein, lipid, and chitosan nanoparticles for drug delivery. J Biomed Mater Res B Appl Biomater. 2008;86: 105-112. doi:10.1002/jbm.b.30994
46. Fathi M, Varshosaz J, Mohebbi M, Shahidi F. Hesperetin-loaded solid lipid nanoparticles and nanostructure lipid carriers for food fortification: preparation, characterization, and modeling. Food Bioprocess Tech. 2013;6:1464-1475. doi:10.1007/s11947-012-0845-2

47. Priyanka K, Sathali AA. Preparation and evaluation of montelukast sodium loaded solid lipid nanoparticles. J Young Pharm. 2012;4:129-137. doi:10.4103/0975-1483.100016

48. Ritger PL, Peppas NA. A simple equation for description of solute release I. Fickian and non-fickian release from non-swellable devices in the form of slabs, spheres, cylinders or discs. J Control Release. 1987;5:23-36. doi:10.1016/0168-3659(87)90034-4

49. Hudzicki J. Kirby-Bauer Disk Diffusion Susceptibility Test Protocol. American Society for Microbiology; 2016. Available from: https:// www.asm.org. Accessed March 17, 2021.

50. Vardakas KZ, Siempos II, Athanassa AZ, Korbila P, Falagas ME. Respiratory fluoroquinolones for the treatment of community acquired pneumonia: a meta-analysis of randomized controlled trials. Can Med Assoc J. 2008;179:1269-1277. doi:10.1503/cmaj. 080358

51. Sreedharan SM, Singh R. Ciprofloxacin functionalized biogenic gold nanoflowers as nanoantibiotics against pathogenic bacterial strains. Int J Nanomedicine. 2019;14:9905. doi:10.2147/IJN.S22 4488

52. Patel KK, Agrawal AK, Anjum MM, et al. DNase-I functionalization of ciprofloxacin-loaded chitosan nanoparticles overcomes the biofilm-mediated resistance of Pseudomonas aeruginosa. Appl Nanosci. 2020;10(2):563-575. doi:10.1007/s13204-019-01129-8

53. Azhdarzadeh M, Lotfipour F, Zakeri-Milani P, Mohammadi G, Valizadeh H. Anti-bacterial performance of azithromycin nanoparticles as colloidal drug delivery system against different gram-negative and gram-positive bacteria. Adv Pharm Bull. 2012;2(1):17. doi:10. 5681/apb.2012.003

54. Mendonça TC, de Paula E, Castro SR, Lancellotti M, Ribeiro LN. Development of nanostructured lipid carriers containing the antimicrobial ciprofloxacin for topical application. Rev Trab Iniciac Cient UNICAMP. 2018;26.

55. Stevanovic M, Uskokovic D. Poly (lactide-co-glycolide)-based micro and nanoparticles for the controlled drug delivery of vitamins. Curr Nanosci. 2009;5:1-14. doi:10.2174/157341309787314566

56. Keshani S, Daud WRW, Nourouzi MM, Namvar F, Ghasemi M. Spray drying: an overview on wall deposition, process and modeling. J Food Eng. 2015;146:152-162. doi:10.1016/j.jfoodeng. 2014.09.004

57. LeClair DA, Cranston ED, Xing Z, Thompson MR. Optimization of spray drying conditions for yield, particle size and biological activity of thermally stable viral vectors. Pharm Res. 2016;33(11): 2763-2776. doi:10.1007/s11095-016-2003-4

58. Learoyd TP, Burrows JL, French E, Seville PC. Chitosan-based spray-dried respirable powders for sustained delivery of terbutaline sulfate. Eur J Pharm Biopharm. 2008;68(2):224-234. doi:10.1016/j. ejpb.2007.04.017

59. Cevher E, Orhan Z, Mülazımoğlu L, et al. Characterization of biodegradable chitosan microspheres containing vancomycin and treatment of experimental osteomyelitis caused by methicillin-resistant Staphylococcus aureus with prepared microspheres. Int J Pharm. 2006;317:127-135. doi:10.1016/j.ijpharm.2006.03.014

60. Tonon RV, Freitas SS, Hubinger MD. Spray drying of açai (Euterpe oleraceae Mart.) juice: effect of inlet air temperature and type of carrier agent. J Food Process Preserv. 2011;35:691-700. doi:10.1111/ j.1745-4549.2011.00518.x

61. He P, Davis SS, Illum L. Chitosan microspheres prepared by spray drying. Int J Pharm. 1999;187:53-65. doi:10.1016/S0378-5173(99) 00125-8

62. Wang L, Zhang Y, Tang X. Characterization of a new inhalable thymopentin formulation. Int J Pharm. 2009;375:1-7. doi:10.1016/j. ijpharm.2009.03.020 
63. Usman MS, El Zowalaty ME, Shameli K, Zainuddin N, Salama M, Ibrahim NA. Synthesis, characterization, and antimicrobial properties of copper nanoparticles. Int J Nanomed. 2013;8:4467.

64. Sullivan DJ, Cruz-Romero M, Collins T, Cummins E, Kerry JP, Morris MA. Synthesis of monodisperse chitosan nanoparticles. Food Hydrocoll. 2018;83:355-364. doi:10.1016/j.foodhyd.2018.05.010

65. Raafat D, Sahl HG. Chitosan and its antimicrobial potential a critical literature survey. Microb Biotechnol. 2009;2(2):186-201.

66. Bharathala S, Singh R, Sharma P. Controlled release and enhanced biological activity of chitosan-fabricated carbenoxolone nanoparticles. Int J Biol Macromol. 2020;164:45-52. doi:10.1016/j.ijbiomac.2020. 07.086

67. Abdou EM, Kandil SM, Morsi A, Sleem MW. In-vitro and in-vivo respiratory deposition of a developed metered dose inhaler formulation of an anti-migraine drug. Drug Deliv. 2019;26(1):689-699. doi:10.1080/10717544.2019.1618419
68. Tena AF, Clarà PC. Deposition of inhaled particles in the lungs. Arch Bronconeumol. 2012;48(7):240-246. doi:10.1016/j.arbr.2012.02.006

69. Wu X, Zhang W, Hayes D J.R, Mansour HM. Physicochemical characterization and aerosol dispersion performance of organic solution advanced spray-dried cyclosporine A multifunctional particles for dry powder inhalation aerosol delivery. Int $J$ Nanomedicine. 2013;8:12691283.

70. Duan J, Vogt FG, Li X, Hayes D J.r, Mansour HM. Design, characterization, and aerosolization of organic solution advanced spray-dried moxifloxacin and ofloxacin dipalmitoylphosphatidylcholine (DPPC) microparticulate/nanoparticulate powders for pulmonary inhalation aerosol delivery. Int J Nanomed. 2013;8:3489-3505. doi:10.2147/IJN.S48631
International Journal of Nanomedicine

\section{Publish your work in this journal}

The International Journal of Nanomedicine is an international, peerreviewed journal focusing on the application of nanotechnology in diagnostics, therapeutics, and drug delivery systems throughout the biomedical field. This journal is indexed on PubMed Central, MedLine, CAS, SciSearch ${ }^{\mathbb{2}}$, Current Contents ${ }^{\mathbb{R}} /$ Clinical Medicine, $^{2}$
Dovepress

Journal Citation Reports/Science Edition, EMBase, Scopus and the Elsevier Bibliographic databases. The manuscript management system is completely online and includes a very quick and fair peer-review system, which is all easy to use. Visit http://www.dovepress.com/ testimonials.php to read real quotes from published authors. 